\title{
MATERIAL TRANSSHIPMENT FOR PRECAST FABRICATION
}

\author{
Chien-Ho KO \\ Department of Civil Engineering, National Pingtung University of Science and Technology, \\ 1 Shuefu Road, Neipu, Pingtung, 91201, Taiwan
}

Received 2 May 2011; accepted 25 Aug. 2011

\begin{abstract}
Materials required for precast fabrication are dissimilar to those cast at construction sites. Fabricators who lack materials must wait until specific suppliers deliver the required materials. The objective of this study is to reduce total material management costs in the supply chain system through the most advantageous transshipment strategies. A material supply chain framework that enables fabricators to implement lateral transshipment is first proposed. Transshipment strategies are then formulated into a mathematical model. The most advantageous transshipment strategies are analyzed using computer simulation. Diverse order lead times, demands, transportation costs, and shortage costs are simulated to approximate operational conditions encountered in supply chain systems. Through various experiments, the most advantageous strategy for precast fabrication industry can be found. In addition, four rules are developed based on simulation results to enhance transshipment decision making. This research is one of the pioneering studies applying lateral transshipment to precast production management.
\end{abstract}

Keywords: precast fabrication; supply chain management; material transshipment; computer simulation.

Reference to this paper should be made as follows: Ko, C.-H. 2013. Material transshipment for precast fabrication, Journal of Civil Engineering and Management 19(3): 335-347.

\section{Introduction}

Precast fabricators strive for business success by delivering products on time. This goal cannot be achieved without flexible and sufficient material supply (Ko, Ballard 2004). Precast fabricators make material plans primarily depending on experience (Ko, Wang 2011; Blakemore, Konda 2010). This unsystematic manner in which plans are made depends on the subjective recognition that material requirements cannot be appropriately targeted for production (Tah, Carr 2001; Vollmann et al. 2004). Material supply has become one of the key issues to enhance company competitiveness (Yeo, Ning 2002; Im et al. 2009).

Precast component design differs from regular structures. Material and accessory parts for precast fabrication are thus dissimilar to those cast at a construction site (Hanlon et al. 2009). Due to special size and dimension requirements, precast materials are difficult to dispatch when fabricators lack materials. Currently, fabricators must wait for the required materials until a specific supplier delivers them to the precast factory. Construction projects are tremendously costly. A tardiness penalty occurs when precast fabricators cannot deliver elements to the construction site on time (Ko 2006; Sambasivan, Soon 2007), also causing business reputation to deteriorate due to late deliveries.

Precast material specifications vary with construction projects. The lead time for ordering materials is longer than that required in regular manufacturing. Precast fabricators must preorder materials before confirming the shop drawing, otherwise, production cannot begin until the materials are acquired (Ko 2011). This scenario extends production makespan and increases the risk for late delivery. Because fabricators preorder material before confirming the shop drawing, they adopt a frequent order strategy that uses small batch sizes to avoid over ordering (Oyetunji, Anderson 2006). Unfortunately, uncertainties in material availability and order lead time frequently result in late material delivery, thereby extending production makespan and increasing the risk for late delivery (Im et al. 2009). The other challenge encountered while making material plans is variations in the material consumption rate, which increases the risk for material shortage (Shu 2001). One possibility for reducing these risks is adopting strategic cooperation among precast factories. Material lateral transshipment is a strategic cooperation that

E-mail: fpecount@yahoo.com.tw 
transships materials from manufacturing plants that have sufficient supplies to others starved for materials. Several studies have pinpointed that lateral material transshipment is efficient and effective in reducing inventory levels, holding costs (HCs), and late delivery risks (Axsäter 1990a, b; Herer, Tzur 2001, 2003).

Previous researches have proven material sharing to be a promising way to provide fabricators with a flexible material supply, especially for industries that manufacture with special materials (Verma, Agarwal 2005; Burton, Banerjee 2005; Lee et al. 2007). Herer and Tzur (2003) focused on investigating dynamic supply chain issues. Their research found that dynamic multi-supply is a deterministic problem solvable in polynomial time. Axsäter (1990a) and Tagaras (1999) proposed lateral transshipment models for retailers through material sharing. However, the transshipment models developed by these two studies ignored transshipment lead time and transportation costs (TCs), which is inappropriate for an industry with long lead time and high TCs, such as the precast concrete industry. Banerjee et al. (2003) analyzed retailer inventory level, frequency of shortage, amount of shortage, and amount of lateral transshipment using computer simulations. Their proposed simulation model did not account for future requirements, which may result in retailer shortages after transshipment. In this case, the frequency of shortage, amount of shortage, and total transportation duration increased. Shu (2001) employed supply chain management in the construction industry and developed a minimum inventory model. However, that model deals with steel material inventory, which is insufficient for the needs of precast fabrication. In addition, the model developed by Shu (2001) was executed in a mass production environment that may increase finished goods inventory and expose the fabricator to the impact of variability (Hopp, Spearman 2000).

The objective of this study is to reduce total material management costs in the supply chain system using a lateral transshipment strategy. The most advantageous strategy is analyzed using computer simulations. The material transshipment strategies analyzed in this study were established by considering material order lead time and the retailer's future demand. The most advantageous strategy is determined according to total supply chain system cost.

Current supply chain management in the precast industry focuses on promoting individual benefits. The literature contains few examples of fabricators applying lateral transshipment strategies to supply chain systems. Construction projects have the characteristics of high price, long duration, a tremendous number of sub-contractors, and complicated interfaces. Although Tagaras (1999), Banerjee et al. (2003) and Herer and Tzur (2003) proposed several lateral transshipment principles. These models focused on general retailers may not be directly applied in the construction industry. Investigations on transshipment strategy analysis for material sharing are scarce in the construction industry.

\section{Review on inventory management and risk pooling}

\subsection{Supply chain management}

Supply chain management (SCM) is a series of actions that manage material supply, production manufacturing, material transshipment, and sales of upstream and downstream suppliers. The purpose of SCM is to minimize manufacturing cost and maximize company profits. The American Production and Inventory Control Society (APICS) dictionary defines SCM as:

Supply Chain Management, as the management of the entire value-added chain, from the supplier to manufacturer right through to the retailer and the final customer. SCM has three primary goals: Reduce inventory, increase transaction speed by exchanging data in real-time, and increase sales by implementing customer requirements more efficiently (Fredendall 2001)

Ross (1998) regarded SCM as a managerial philosophy that links internal and external partners of the enterprise to create customer value. Cooper (1994) identified SCM as an integrated decision that considers a systematic process from production, delivery, and dispatch. Bloomberg et al. (1998) defined SCM as a logistical method that delivers products from the upstream supplier to the customer.

SCM is a series of methods that effectively integrates the supplier, fabricators, and sales to achieve production optimization (Toktaş-Palut, Ülengin 2011). The goal is to deliver the right products to the right place at the right time with minimum system cost.

\subsection{Inventory management}

Inventory is an amount of accumulated products used to fulfill future requirements, which can be categorized into periodic, work in process (WIP), safety stock, seasonal, and static inventories (Ko 2010). Inventory exists for the following purposes (Axsäter 2006): (1) to reach economics of scale; (2) to balance supply and demand; (3) to specialize; (4) to buffer demand uncertainty and order uncertainty; and (5) to buffer transshipment. Given these purposes, inventory is an idle resource existing for the production life cycle, set for future needs. Ineffective use of inventory is a waste, because its value can be lost through wear and tear, loss, and expiration (Hopp, Spearman 2000). Inventory is inevitable in enterprises. However, a high inventory wastes operational cost, whereas a low inventory increases reorder cost. Zhang (1992) identified the objective of inventory management as effectively managing stocks. To achieve that goal, the 
management purpose and objective should be clear, to facilitate applying the appropriate control methods. Inventory typically exists only in normal business activities, for example preparation, production, and sale.

\subsection{Inventory control methods}

The method that reviews inventory affects the inventory-level measurement accuracy. Inventory reviewing methods include two categories: continuous review and periodic review, where (s, Q) and (s, S) are continuous reviews and $(\mathrm{R}, \mathrm{S})$ and $(\mathrm{R}, \mathrm{s}, \mathrm{S})$ are periodic reviews. The following explains these four reviewing methods (Axsäter 2006; Silver et al. 1998):

(1) $(s, Q)$ method. This method reorders Q amount when the inventory level drops to reorder point $\mathrm{s}$. The advantage of using this method is that it is simple and easy to use. However, because this method is inflexible, it fails to provide sufficient material once the requirement grows larger than Q. This method is frequently used when the demand for a downstream supplier can be predicted.

(2) $(s, S)$ method. When the inventory level meets the reorder point $\mathrm{s}$, the inventory is filled with amount $\mathrm{Q}$ to reach level $\mathrm{S}$ (i.e. $\mathrm{S}=\mathrm{s}+\mathrm{Q}$ ). The advantage of using this method is that the total cost of managing the inventory is more economical than using (s, Q). However, the calculation process for this method is more complex than using (s, Q). Because ordering $\mathrm{Q}$ amount varies, an abundance or shortage occurs when the fabricator inaccurately predicts future demand.

(3) $(R, S)$ method. The $(\mathrm{R}, \mathrm{S})$ reorders $\mathrm{Q}$ amount to reach inventory level $\mathrm{S}$ at every time period $R$. Precast fabricators frequently use this method when they have specific suppliers. Although this method can be used to track demand trends corresponding with time, the order cost may be increased if $\mathrm{R}$ is short. Inventory shortages may also occur before reorder.

(4) $(R, s, S)$ method. This method combines $(\mathrm{s}, \mathrm{S})$ and $(\mathrm{R}, \mathrm{S})$, which reviews the inventory level at every time period $\mathrm{R}$. When the inventory level drops to $\mathrm{s}$, fabricators reorder $\mathrm{Q}$ to reach level S. The benefit of using this method is that fabricators can pre-evaluate the reorder amount according to future requirements. The total cost for using this method is relatively low, if accurately evaluating future requirements.

\subsection{Lateral transshipment}

Lateral transshipment (also known as material sharing) is a concept that reduces system variability by transshipping materials from manufacturers who have sufficient supplies to others starved for materials. The benefits of adopting lateral transshipment include reducing average inventory level, reducing inventory cost, and reducing safety stock level. The following explains recent investigations on material lateral transshipment:

(1) Axsäter (1990b) investigated a two-tier inventory problem between multiple retailers using a central warehouse. Axsäter assumed a fixed-order lead time and the demand obeys a Poisson distribution. That study also constrained lateral transshipment by executing from a central warehouse to a retailer. In the same year, another report (Axsäter 1990a) extended the two-tier inventory problem to three layers, transshipping materials between retailers. The primary objective of these studies was to reduce material shortages.

(2) Tagaras (1999) regarded that emergency orders require extra cost and time. Tagaras proposed a pooling policy between retailers. Retailers could reduce shortage and inventory costs through sharing inventory resources. Tagaras' risk pooling assumed all retailers used a periodic ordering system. Since that model had not considered emergency orders, retailers could only ask for help from other retailers when they lacked materials. Other retailers transshipped extra inventory to those starved for materials. This policy is called lateral transshipment. Using lateral transshipment, $\mathrm{HCs}$ for retailers with extra inventory and shortage costs (SC) for those lacking inventory can be reduced. This concept also reduces emergency order costs. However, Tagaras (1999) did not consider order lead time and the cost for implementing lateral transshipment.

(3) Banerjee et al. (2003) concluded that adopting lateral transshipment could dramatically reduce material shortage risk. Those authors felt that placing emergency orders consumed more cost and time. Their transshipment assumed that retailer demand obeyed a normal distribution. The model developed by Banerjee et al. (2003) used a periodic order system. They analyzed the uncertainty in the supply chain with low demand and high demand using computer simulation techniques. Their research finding was consistent with previous studies, that is lateral transshipment reduces holding, inventory costs, and material shortage risks. However, their study did not consider future requirements after transshipment, which means that inventory shortage may occur after lateral transshipment. As a result, cost, frequency, and transshipment time may be increased using their model.

(4) Herer and Tzur (2003) focused on studying dynamic deterministic demand in the supply chain system. Their research considered factors including procurement cost, TC, and inventory cost. Materials were dispatched using a central inventory control system. Their study found that dynamic multi-supply dispatching is a deterministic problem that can be solved within polynomial time. Herer and Tzur (2003) thus proposed a heuristic algorithm to solve that model. 


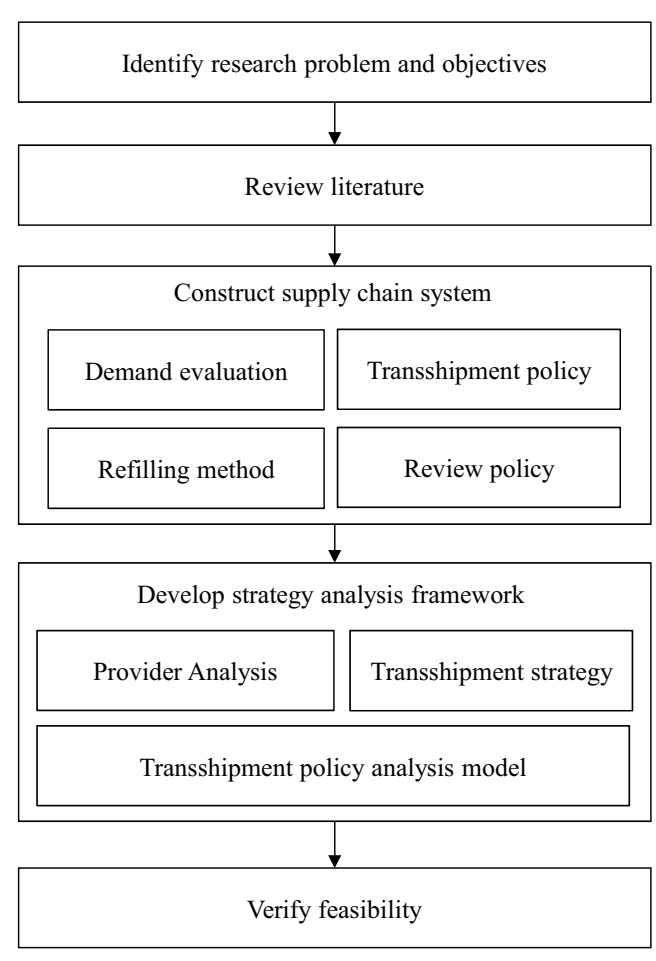

Fig. 1. Research flow

\section{Research methodology}

In order to systematically achieve research objectives, research methodology is elaborated, summarized in Figure 1. Difficulties encountered in precast fabrication are first surveyed. Potential approaches for overcoming these difficulties are investigated. Supply chain management, inventory control methods, and lateral transshipment theories are reviewed in this step. A supply chain system is then developed to drive the material transshipment. In this activity, uncertain demand of precast fabricator is established. A review policy is determined to monitor inventory level. Lateral transshipment can be launched if it conforms to transshipment policy. Finally, refilling method is analyzed when transshipping materials.

To analyze the most advantageous strategy for material transshipment in the supply chain system, strategy analysis framework is constructed. Which precast fabricator eligible for provider is first selected.

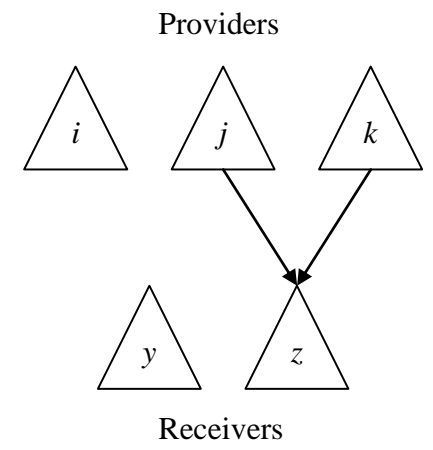

Fig. 3. Scheme of random policy

Six strategies are developed according to potentially advantageous transshipment alternatives. The most advantageous strategy is analyzed using simulation technique which is programmed using eM-Plant software with the Simtalk ${ }^{\mathrm{TM}}$ language. Finally, feasibility of the developed transshipment analysis model is accessed using precast rebar cases.

\section{Supply chain system}

To enable fabricators to implement material transshipment, this study constructs a supply chain framework. The framework consists of a central warehouse with multiple fabricators, explained as follows:

(1) Uncertain demand evaluation. This evaluation assumes that the precast fabricator's demand obeys a normal distribution. To represent uncertain demands in a supply chain system, two kinds of uniform distributions are used. A stable demand with low variability is formulated as $D_{i} \pm 0.333 D_{i}$, whereas an unstable one with high variability uses $D_{i} \pm 0.667 D_{i}$. Only positive demands are considered in this study. Negative demand values are replaced by 0 in the analysis process.

(2) Review policy. This system adopts a periodic review to monitor inventory level and chooses a method for reducing review cost due to repetitive monitoring. Precast fabricators reorder amount Q to reach inventory level $\mathrm{S}$ every time interval $\mathrm{R}$ (e.g. 30 days), as depicted in Figure 2.

(3) Transshipment policy. This study defines factories with sufficient inventory for others starved

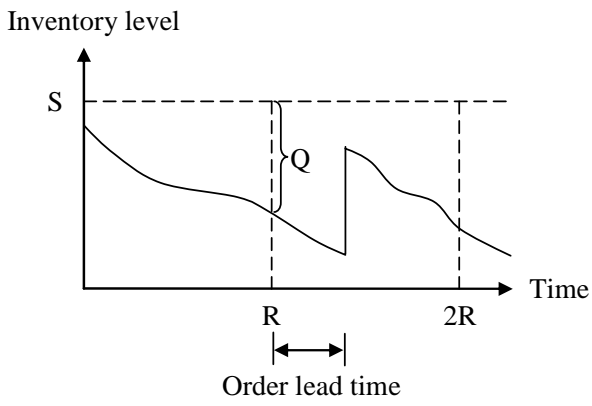

Fig. 2. Scheme of periodic review

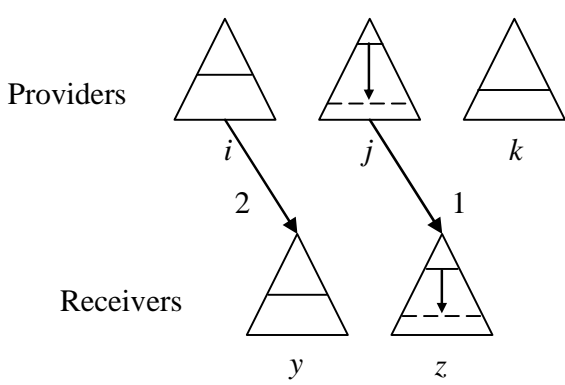

Fig. 4. Example of TBAPR I 


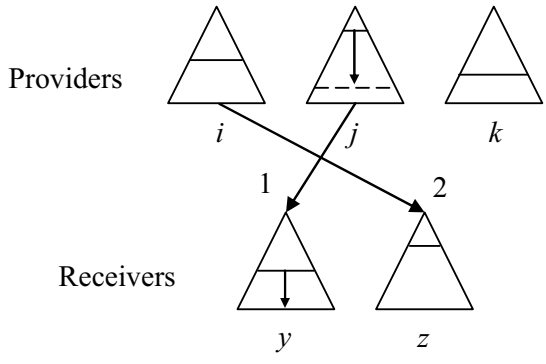

Fig. 5. Example of TBAPR II

for materials as providers and defines manufacturers starved for materials as receivers. Lateral transshipment will not be executed if receivers can replenish their inventory in the next day. As a result, materials are transshipped to other receivers eager for the material. Transshipment terminates when all receivers have sufficient materials or all providers cannot ship any more materials.

(4) Refilling method. This study uses an orderup-to method to refill stocks, that is a manufacturer $i$ orders amount $Q_{i}$ to reach inventory level $S_{i}$ when reviewing the inventory. Calculation of $S_{i}$ is formulated in Eqn (1):

$$
S_{i}=d_{i} \times(R+L)+S S,
$$

where $d_{i}$ denotes the expected daily consuming rate of material; $R$ is reorder interval; $L$ represents order lead time; and $S S$ is a minimum safety stock defined in Eqn (2):

$$
S S=k \times \delta \times \sqrt{L},
$$

where $k$ is a safety factor and $\delta$ denotes standard deviation of demand. Equation (2) is an empirical function that inventory management frequently uses (Ameli et al. 2009; Manzini et al. 2008).

(5) Average demand evaluation. Estimation of fabricator $i$ 's average demand $\left(D_{i} R\right)$ for a review period in $N$ retailers supply chain system is calculated using Eqn (3) proposed by Banerjee et al. (2003):

$$
\begin{aligned}
& D_{i} R=(N-1) \times 100+(i-1) \frac{(N-1) \times 100}{(N-1)}, \\
& \text { for } i=1,2,3, \cdots, N-1 .
\end{aligned}
$$

\section{Strategy analysis framework}

\subsection{Provider analysis}

The transshipment strategy analysis process is composed of two stages. The first stage critiques whether a manufacturer has sufficient material for others. If any providers exist, appropriate transshipment strategies

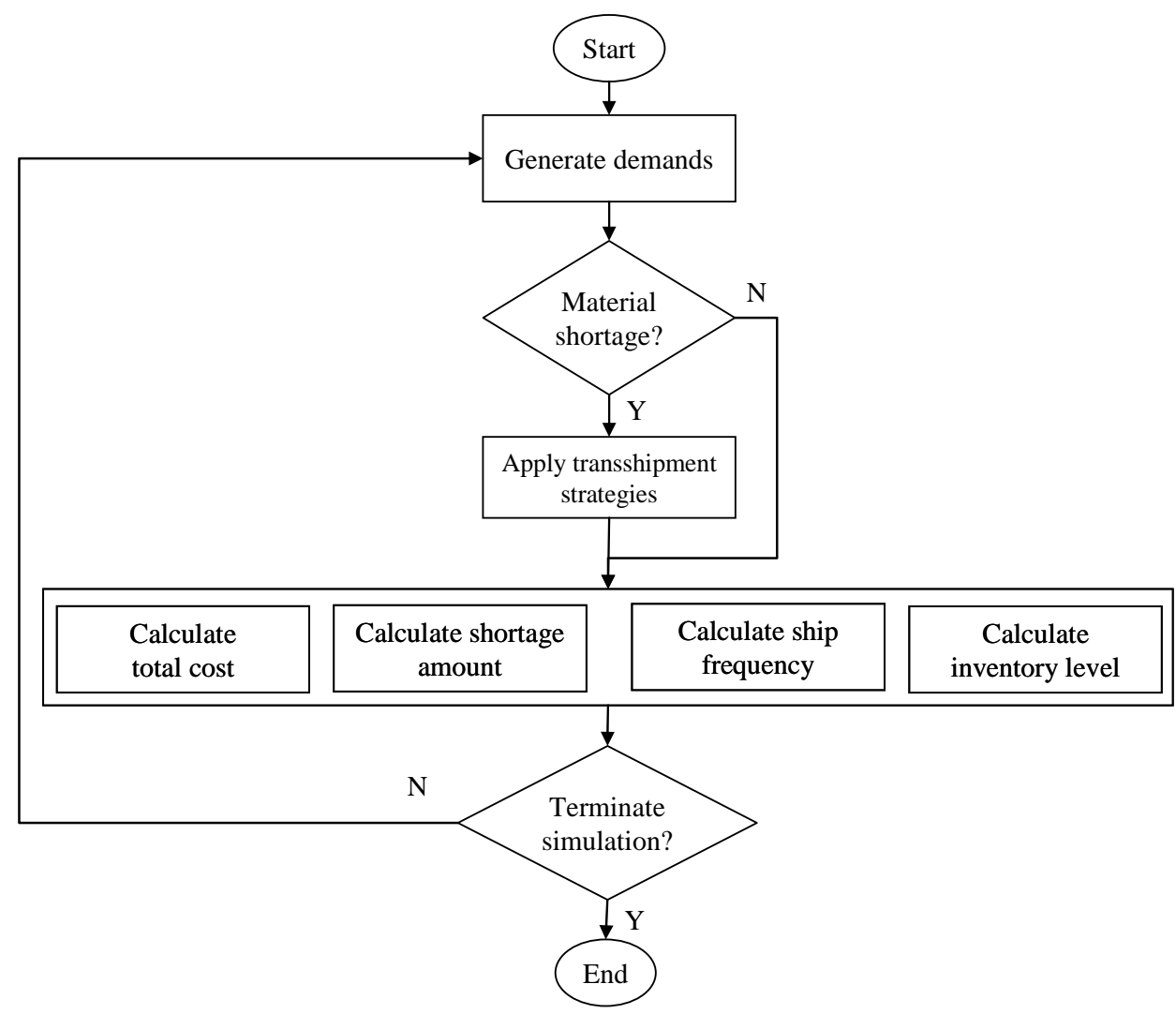

Fig. 6. Simulation process 
are analyzed in the second stage. Whether a manufacturer is qualified as a provider is estimated by its demand from the current time point to the next review time point. If the current inventory is sufficient for that interval, the retailer is qualified. Otherwise, providers may become receivers after transshipment. A material shortage can be pre-warned using Eqn (4):

$$
I_{j}(t) \leq\left(d_{j} \times 1\right) \text { for } j=1,2, \cdots, J,
$$

where $I_{j}(t)$ denotes inventory level of the manufacturer $j$ at the time point $t$. Equation (4) is used to pre-warn the manufacturer $j$ that lacks materials one day after the time point $t$. If Eqn (4) is true, the retailer needs transshipment. The amount available for transshipment noted as $S H_{j}(t)$ is calculated using Eqn (5):

$$
S H_{j}(t)=\left(d_{j} \times 1\right)-I_{j}(t), \forall j
$$

The next step evaluates whether a manufacturer is qualified as a provider. Equation (6) is used to verify that the manufacturer has sufficient materials for future demands:

$$
I_{k}(t)>E\left[I_{i}(t)\right]
$$

Future demand $\left(E\left[I_{i}(t)\right]\right)$ is calculated using Eqn (7):

$$
E\left[I_{i}(t)\right]=d_{i} \times(R+L), \forall i
$$

where $d_{i} \times(R+L)$ is the required amount of material from current time point $t$ to the next refill. If a retailer is qualified as a provider, the amount of material $A_{k}(\mathrm{t})$ is shipped, formulated in Eqn (8):

$$
A_{k}(t)=I_{k}(t)-E\left[I_{k}(t)\right], k=1,2, \cdots, K .
$$

\subsection{Transshipment strategy}

Lateral transshipment uses shipping materials from fabricators (providers) with sufficient materials to those (receivers) eager for materials. However, materials could be transshipped in many ways, such as randomly selecting providers and receivers, or transshipping materials from the most sufficient providers to those with the most shortage. Determining an appropriate strategy is crucial to successfully implementing lateral transshipment. Axsäter (1990a, b) and Banerjee et al. (2003) proposed priorities for emergency transshipment. Unfortunately, their strategies ignored future demands for the providers themselves. As a result, the providers may fall victim to material shortage after shipment. This study adopts the transshipment strategies proposed by Axsäter (1990a, b), Banerjee et al. (2003), and Li (2005) by considering future demands and order lead times. The following explains the six transshipment strategies analyzed in this study:

(1) No lateral shipments (NLS). This strategy does not ship materials to any fabricators when material shortages occur, which is regarded as a basis for comparison with those executing lateral transshipments. In this strategy, manufacturers eager for materials refill inventory through periodic review.

(2) Random policy $(R A)$. This strategy randomly selects providers and receivers, as schematically displayed in Figure 3. Suppose manufacturers $i, j$, and $k$ are qualified providers, and manufacturers $y$ and $z$ are receivers. This strategy randomly selects $j$ as a provider and randomly selects $z$ as a receiver. If provider $j$ cannot ship materials to receiver $z$ with a sufficient amount, the strategy randomly selects another provider (noted as $k$ in Fig. 3). The fabricator's future demand is approximated using an average demand.

(3) Make lateral transshipments based on availability priority policy I (TBAPR I). This strategy determines provider and receiver priority based on

\begin{tabular}{|c|c|c|c|c|c|c|c|}
\hline \multirow[b]{2}{*}{ Number } & \multicolumn{3}{|c|}{$\begin{array}{l}\text { Order lead } \\
\text { time }\end{array}$} & \multirow[b]{2}{*}{$\mathrm{HC}$} & \multicolumn{2}{|l|}{ Cost } & \multirow{2}{*}{$\begin{array}{l}\text { Demand } \\
\text { variability }\end{array}$} \\
\hline & L1 & L2 & L3 & & TRC & $\mathrm{SC}$ & \\
\hline $1-1$ & 1 & 1 & 1 & 1 & 4 & 1 & Low \\
\hline $1-2$ & 1 & 1 & 1 & 1 & 9 & 1 & Low \\
\hline $1-3$ & 1 & 1 & 1 & 1 & 9 & 3 & Low \\
\hline $1-4$ & 1 & 1 & 1 & 1 & 90 & 10 & Low \\
\hline $1-5$ & 1 & 1 & 1 & 1 & 20 & 100 & Low \\
\hline $2-1$ & 3 & 3 & 3 & 1 & 4 & 1 & Low \\
\hline $2-2$ & 3 & 3 & 3 & 1 & 9 & 1 & Low \\
\hline $2-3$ & 3 & 3 & 3 & 1 & 9 & 3 & Low \\
\hline $2-4$ & 3 & 3 & 3 & 1 & 90 & 10 & Low \\
\hline $2-5$ & 3 & 3 & 3 & 1 & 20 & 100 & Low \\
\hline $3-1$ & 3 & 1 & 1 & 1 & 4 & 1 & Low \\
\hline $3-2$ & 3 & 1 & 1 & 1 & 9 & 1 & Low \\
\hline $3-3$ & 3 & 1 & 1 & 1 & 9 & 3 & Low \\
\hline $3-4$ & 3 & 1 & 1 & 1 & 90 & 10 & Low \\
\hline $3-5$ & 3 & 1 & 1 & 1 & 20 & 100 & Low \\
\hline $4-1$ & 1 & 1 & 1 & 1 & 4 & 1 & High \\
\hline $4-2$ & 1 & 1 & 1 & 1 & 9 & 1 & High \\
\hline $4-3$ & 1 & 1 & 1 & 1 & 9 & 3 & High \\
\hline 4-4 & 1 & 1 & 1 & 1 & 90 & 10 & High \\
\hline $4-5$ & 1 & 1 & 1 & 1 & 20 & 100 & High \\
\hline $5-1$ & 3 & 3 & 3 & 1 & 4 & 1 & High \\
\hline $5-2$ & 3 & 3 & 3 & 1 & 9 & 1 & High \\
\hline $5-3$ & 3 & 3 & 3 & 1 & 9 & 3 & High \\
\hline $5-4$ & 3 & 3 & 3 & 1 & 90 & 10 & High \\
\hline $5-5$ & 3 & 3 & 3 & 1 & 20 & 100 & High \\
\hline $6-1$ & 3 & 1 & 1 & 1 & 4 & 1 & High \\
\hline $6-2$ & 3 & 1 & 1 & 1 & 9 & 1 & High \\
\hline $6-3$ & 3 & 1 & 1 & 1 & 9 & 3 & High \\
\hline $6-4$ & 3 & 1 & 1 & 1 & 90 & 10 & High \\
\hline $6-5$ & 3 & 1 & 1 & 1 & 20 & 100 & High \\
\hline
\end{tabular}
material sufficient and the shortage amount. Providers with the most sufficient ship materials to those with the most shortage to immediately replenish reserves,

Table 1. Parameters for three manufacturers

Note: The column "Number" is categorized using a combination of the transportation and shortage costs $(S C, T R C)$. Demand variability "Low" and "High" represents $D_{i} \pm 0.667 D_{i}$ and $D_{i} \pm$ $0.667 D_{i}$, respectively. 
Table 2. Total cost for the three retailers system

\begin{tabular}{|c|c|c|c|c|c|c|}
\hline \multirow[b]{2}{*}{ Number } & \multirow[b]{2}{*}{ NLS } & \multicolumn{4}{|c|}{ Transshipment strategy } & \multirow[b]{2}{*}{ MA } \\
\hline & & $\mathrm{RA}$ & TBAPR I & TIE & TBAPR II & \\
\hline $1-1$ & 383703.40 & 383272.24 & 382912.77 & 383233.92 & 383138.25 & 383091.10 \\
\hline $1-2$ & 387890.01 & 386974.58 & 386265.39 & 386935.88 & 386750.63 & 386619.69 \\
\hline $1-3$ & 387692.35 & 386820.49 & 386184.33 & 386781.81 & 386535.11 & 386452.97 \\
\hline $1-4$ & 459879.64 & 450107.24 & 441261.22 & 450062.22 & 445403.58 & 445148.41 \\
\hline $1-5$ & 401032.18 & 401716.35 & 403068.33 & 401576.22 & 401767.24 & 401829.54 \\
\hline $2-1$ & 398556.50 & 398305.69 & 398140.12 & 398265.86 & 398231.70 & 398207.73 \\
\hline $2-2$ & 401881.45 & 401326.37 & 401002.71 & 401286.24 & 401237.15 & 401229.82 \\
\hline $2-3$ & 401851.63 & 401410.26 & 401114.21 & 401370.12 & 401345.48 & 401308.92 \\
\hline $2-4$ & 437221.24 & 432458.02 & 429964.97 & 432414.78 & 431441.73 & 430907.81 \\
\hline $2-5$ & 407076.88 & 407416.58 & 408026.34 & 407375.83 & 407701.69 & 407923.01 \\
\hline $3-1$ & 387032.57 & 386667.77 & 386447.51 & 386589.10 & 386556.21 & 386474.75 \\
\hline $3-2$ & 389539.54 & 388867.31 & 388362.81 & 388728.42 & 388615.42 & 388419.55 \\
\hline $3-3$ & 390015.13 & 389540.75 & 389008.21 & 389421.79 & 389239.37 & 389166.69 \\
\hline $3-4$ & 450903.10 & 445015.44 & 438894.02 & 443370.93 & 442529.01 & 440130.88 \\
\hline $3-5$ & 401097.43 & 401171.29 & 402263.51 & 401131.17 & 401528.69 & 401934.01 \\
\hline $4-1$ & 390474.90 & 388593.06 & 387690.80 & 388554.20 & 388496.32 & 388370.74 \\
\hline $4-2$ & 399418.17 & 395887.97 & 393491.29 & 395848.38 & 395520.64 & 395436.73 \\
\hline $4-3$ & 400056.64 & 397039.64 & 394619.07 & 396999.93 & 396599.79 & 396140.55 \\
\hline $4-4$ & 567653.40 & 535974.35 & 508950.09 & 535920.75 & 524879.26 & 521369.65 \\
\hline $4-5$ & 424469.02 & 432574.42 & 433438.78 & 428531.76 & 429067.76 & 431219.78 \\
\hline $5-1$ & 404381.83 & 402998.55 & 402420.84 & 402958.25 & 402832.74 & 402531.90 \\
\hline $5-2$ & 410166.11 & 407666.82 & 405570.34 & 407626.06 & 407330.80 & 407062.45 \\
\hline $5-3$ & 409762.05 & 407366.77 & 406323.49 & 407326.03 & 407185.97 & 407140.96 \\
\hline $5-4$ & 533791.99 & 508596.98 & 490123.22 & 508546.12 & 504614.33 & 500109.61 \\
\hline $5-5$ & 430886.43 & 434032.15 & 437397.70 & 433988.74 & 434263.61 & 434846.01 \\
\hline $6-1$ & 391888.67 & 390228.18 & 389470.37 & 390139.16 & 390095.17 & 389862.29 \\
\hline $6-2$ & 401271.81 & 398309.04 & 396828.15 & 398069.21 & 397446.96 & 397132.80 \\
\hline $6-3$ & 403022.42 & 400508.01 & 399057.97 & 400267.96 & 399968.56 & 399416.53 \\
\hline $6-4$ & 550352.54 & 522579.35 & 505097.89 & 521827.10 & 514558.43 & 509470.53 \\
\hline $6-5$ & 427167.27 & 434080.77 & 434150.03 & 430937.67 & 431603.46 & 433588.11 \\
\hline
\end{tabular}

Note: Unit in this table is one per unit holding cost.

thereby reducing SC. The fabricator's future demand is estimated by an average demand. Using Figure 4 as an example, the horizontal lines denote the sufficiency and shortage levels for the provider and receiver, respectively. Applying this strategy, manufacturer $j$, who has most sufficiency, is determined to ship material to manufacturer $z$, who has the most shortage. After the first shipment, manufacturer $i$ becomes a new provider and manufacturer $y$ becomes a new receiver. The transshipment repeats until reaching the termination condition.

The process is summarized as follows:

Step 1: Material sufficiency is ranked from high to low $\left(A_{[1]}(t) \geq A_{[2]}(t) \geq \ldots \geq A_{[\mathrm{k}]}(t)\right)$, and material shortage is ranked from high to low $\left(\mathrm{SH}_{[1]}(t) \geq S H_{[2]}\right.$ $\left.(t) \geq \ldots \geq S H_{[\mathrm{k}]}(t)\right)$;

Step 2: Calculate the amount available for shipment using Eqn (9):

$$
Q_{[1][1]}=\min \left\{A_{[1]}(t), S H_{[1]}(t)\right\}
$$

Step 3: Ship the material if the receiver cannot replenish the required materials by the next day; and
Step 4: Return to step 1 if $A_{[1]}(t) \times S H_{[1]}(t)>0$, otherwise terminate the transshipment process.

(4) Make lateral transshipments based on availability priority policy II (TBAPR II). Another strategy for reducing material shortage impact is to ship material from those with the greatest material sufficiency to those with the most exposure to shortage. This strategy reduces transshipment frequency, and the manufacturer's future demand is estimated using the same method as TBAPR I and RA. Using Figure 5 as an example, at the first transshipment, manufacturer $j$, who has the most sufficiency, is selected to ship material to manufacturer $y$, who has the greatest shortage exposure. After the first shipment, manufacturer $i$ becomes a new provider and manufacturer $z$ becomes a new receiver. Transshipment terminates when all receivers have sufficient materials or all providers cannot ship any more materials. The following four steps summarize the process:

Step 1: Rank material sufficiency from high to low and material shortage from low to high $\left(S H_{[1]}(t) \leq\right.$ $\left.S H_{[2]}(t) \leq \ldots \leq S H_{[\mathrm{k}]}(t)\right)$; 
Table 3. Shortage amount in the three retailers system

\begin{tabular}{|c|c|c|c|c|c|c|}
\hline \multirow[b]{2}{*}{ Number } & \multirow[b]{2}{*}{ NLS } & \multicolumn{4}{|c|}{ Transshipment strategy } & \multirow[b]{2}{*}{ MA } \\
\hline & & RA & TBAPR I & TIE & TBAPR II & \\
\hline $1-1$ & -408.72 & -327.24 & -260.33 & -310.88 & -298.35 & -296.05 \\
\hline $1-2$ & -327.36 & -244.69 & -173.57 & -232.45 & -220.20 & -209.27 \\
\hline $1-3$ & -364.14 & -280.53 & -215.22 & -266.51 & -249.56 & -249.19 \\
\hline $1-4$ & -354.40 & -270.79 & -202.16 & -257.25 & -224.55 & -224.37 \\
\hline $1-5$ & -412.76 & -339.03 & -228.53 & -322.08 & -312.62 & -292.81 \\
\hline $2-1$ & -171.12 & -127.14 & -93.51 & -120.78 & -113.26 & -110.92 \\
\hline $2-2$ & -156.98 & -107.69 & -78.71 & -102.30 & -98.60 & -98.18 \\
\hline $2-3$ & -154.86 & -111.94 & -77.59 & -106.35 & -103.19 & -100.14 \\
\hline $2-4$ & -147.86 & -101.39 & -78.89 & -96.32 & -91.47 & -87.64 \\
\hline $2-5$ & -177.21 & -130.14 & -95.62 & -122.13 & -120.35 & -108.66 \\
\hline $3-1$ & -254.50 & -181.20 & -125.81 & -172.14 & -155.84 & -131.74 \\
\hline $3-2$ & -295.35 & -232.44 & -182.18 & -220.82 & -208.45 & -186.59 \\
\hline $3-3$ & -250.02 & -209.60 & -148.23 & -199.12 & -168.93 & -162.83 \\
\hline $3-4$ & -295.27 & -237.38 & -185.04 & -225.51 & -214.76 & -188.13 \\
\hline $3-5$ & -285.10 & -228.60 & -182.35 & -217.17 & -210.17 & -191.83 \\
\hline $4-1$ & -913.86 & -700.12 & -553.64 & -665.12 & -669.33 & -691.00 \\
\hline $4-2$ & -950.87 & -753.28 & -597.98 & -715.62 & -692.91 & -710.48 \\
\hline $4-3$ & -909.28 & -731.52 & -568.86 & -694.95 & -695.19 & -656.49 \\
\hline $4-4$ & -900.06 & -707.48 & -542.56 & -672.11 & -636.45 & -613.88 \\
\hline $4-5$ & -840.63 & -692.75 & -540.79 & -658.11 & -646.32 & -570.77 \\
\hline $5-1$ & -608.30 & -435.39 & -341.89 & -420.62 & -417.74 & -366.59 \\
\hline $5-2$ & -611.04 & -463.12 & -327.77 & -439.96 & -429.34 & -412.37 \\
\hline $5-3$ & -653.26 & -488.29 & -412.27 & -463.88 & -460.95 & -454.75 \\
\hline $5-4$ & -657.82 & -494.00 & -374.87 & -469.30 & -467.77 & -433.69 \\
\hline $5-5$ & -602.36 & -463.14 & -347.03 & -459.99 & -451.31 & -423.86 \\
\hline $6-1$ & -851.63 & -679.51 & -534.12 & -653.29 & -643.92 & -617.05 \\
\hline $6-2$ & -818.34 & -665.96 & -570.94 & -630.41 & -611.43 & -586.75 \\
\hline $6-3$ & -739.91 & -572.92 & -430.86 & -542.02 & -527.34 & -493.93 \\
\hline $6-4$ & -760.00 & -574.17 & -446.73 & -543.21 & -519.31 & -482.62 \\
\hline $6-5$ & -782.06 & -643.75 & -498.21 & -611.57 & -575.49 & -531.45 \\
\hline
\end{tabular}

Note: Unit in this table is one per unit holding cost.

Step 2: Calculate the shipment amount using Eqn (9);

Step 3: Ship the material if the receiver cannot replenish the required materials by the next day and;

Step 4: Return to step 1 if $A_{[1]}(t) \times S H_{[1]}(t)>0$, otherwise terminate the transshipment process.

(5) Make lateral transshipments using the inventory equalization policy (TIE). This strategy enhances overall supply chain system efficiency. TIE determines the fabricator's sufficiency by considering the system demands and inventories. This policy redistributes stocks to match the ratio of average demand for each retailer whenever there are retailers with less than desirable stock levels. The TIE policy is also a proactive policy based on the inventory balancing or equalization concept through stock redistribution. Equation (10) formulates the expected equalized inventory level for manufacturer $i$ for TIE. If the actual inventory level for manufacturer $i$ is more than the expected equalized inventory level, manufacturer $i$ becomes a provider. Conversely, manufactures are receivers if their actual inventory level is less than the expected equalized level. After determining providers and receivers in the supply chain system, TIE ships materials from providers with the most sufficiency to those with the greatest shortage. The transshipment procedure is the same as TBAPR I.

$$
E\left[I_{i}(t)\right]=\frac{\left[\sum_{i=1}^{N} I_{i}(t)\right]}{\sum_{i=1}^{N}\left(d_{i} \times 1\right)}\left(d_{i} \times 1\right) .
$$

(6) Moving average (MA) policy. To consider future demands for manufactures, this research adopts the MA method to predict the next demand. This strategy ships materials from providers with the most sufficiency to those with the greatest shortage by considering future demands. The MA is a simple and frequently used method to predict future demands (Ula, Smadi 2003), relieving fluctuation due to untraceable movements. The average of the previous three demands $\left(\mu_{i}\right)$ is used as the next demand, as 
Table 4. Transshipment frequency in the three retailers system

\begin{tabular}{|c|c|c|c|c|c|c|}
\hline \multirow[b]{2}{*}{ Number } & \multirow[b]{2}{*}{ NLS } & \multirow[b]{2}{*}{ RA } & \multicolumn{3}{|c|}{ Transshipment strategy } & \multirow[b]{2}{*}{ MA } \\
\hline & & & TBAPR I & TIE & TBAPR II & \\
\hline $1-1$ & 0.00 & 5.60 & 9.06 & 6.11 & 7.79 & 8.37 \\
\hline $1-2$ & 0.00 & 5.43 & 7.24 & 6.82 & 5.78 & 7.24 \\
\hline $1-3$ & 0.00 & 5.30 & 8.59 & 6.22 & 6.33 & 7.39 \\
\hline $1-4$ & 0.00 & 5.06 & 8.65 & 7.24 & 6.55 & 8.93 \\
\hline $1-5$ & 0.00 & 5.31 & 9.66 & 6.09 & 6.47 & 8.52 \\
\hline $2-1$ & 0.00 & 2.79 & 4.66 & 3.73 & 3.72 & 3.29 \\
\hline $2-2$ & 0.00 & 2.45 & 4.25 & 3.16 & 3.52 & 4.53 \\
\hline $2-3$ & 0.00 & 2.32 & 4.25 & 3.08 & 2.54 & 4.36 \\
\hline $2-4$ & 0.00 & 2.97 & 4.82 & 3.95 & 2.62 & 3.51 \\
\hline $2-5$ & 0.00 & 3.42 & 4.59 & 3.23 & 3.22 & 3.75 \\
\hline $3-1$ & 0.00 & 4.75 & 5.27 & 4.19 & 5.03 & 5.46 \\
\hline $3-2$ & 0.00 & 3.77 & 5.09 & 4.75 & 5.54 & 5.70 \\
\hline $3-3$ & 0.00 & 3.98 & 5.64 & 3.27 & 4.07 & 5.04 \\
\hline $3-4$ & 0.00 & 3.78 & 5.21 & 4.99 & 5.85 & 5.89 \\
\hline $3-5$ & 0.00 & 3.26 & 5.47 & 3.52 & 4.52 & 5.35 \\
\hline $4-1$ & 0.00 & 13.04 & 18.60 & 13.77 & 14.89 & 16.00 \\
\hline $4-2$ & 0.00 & 13.62 & 19.00 & 14.22 & 13.29 & 15.82 \\
\hline $4-3$ & 0.00 & 13.79 & 18.12 & 13.71 & 13.77 & 15.03 \\
\hline 4-4 & 0.00 & 13.64 & 19.10 & 13.19 & 14.28 & 16.90 \\
\hline $4-5$ & 0.00 & 12.09 & 17.30 & 13.46 & 14.06 & 15.03 \\
\hline $5-1$ & 0.00 & 9.21 & 13.51 & 10.60 & 9.69 & 12.36 \\
\hline $5-2$ & 0.00 & 10.11 & 14.28 & 11.55 & 10.29 & 11.01 \\
\hline $5-3$ & 0.00 & 9.65 & 12.41 & 10.27 & 8.81 & 10.95 \\
\hline $5-4$ & 0.00 & 9.68 & 13.42 & 10.78 & 10.49 & 11.58 \\
\hline $5-5$ & 0.00 & 9.14 & 12.90 & 9.81 & 9.85 & 10.33 \\
\hline $6-1$ & 0.00 & 11.22 & 17.41 & 11.75 & 13.71 & 15.65 \\
\hline $6-2$ & 0.00 & 11.93 & 14.50 & 11.64 & 12.64 & 14.49 \\
\hline $6-3$ & 0.00 & 12.33 & 14.33 & 12.21 & 12.32 & 15.65 \\
\hline $6-4$ & 0.00 & 11.15 & 15.26 & 11.68 & 12.54 & 14.35 \\
\hline $6-5$ & 0.00 & 12.89 & 15.30 & 13.47 & 14.42 & 15.93 \\
\hline
\end{tabular}

Note: Unit in this table is one per unit holding cost.

formulated in Eqn (11). The transshipment procedure is the same as TBAPR I:

$$
E\left[I_{i}(t)\right]=\frac{\sum_{i=n-3}^{n} \mu_{i}}{3}, \text { for } i=1,2, \cdots, N
$$

\subsection{Transshipment policy analysis model}

Computer simulation was used to analyze the most advantageous transshipment strategy for the supply chain system. This research developed the simulation using eM-Plant software with the Simtalk ${ }^{\mathrm{TM}}$ language. Different-sized supply chain systems were constructed in the simulation. This study assumes that a central warehouse periodically ships materials to fabricators. The computer simulation analyzes the total cost, shortage amount, transshipment frequency, and inventory level. Figure 6 displays the simulation process, implemented on a day-by-day basis and terminated when the program reaches the assigned period. This process also represents the logic flow of analyzing transshipment strategies. The total cost for the supply chain system (noted as TC) includes transportation (TRC), holding $(H C)$, and $S C$, represented in Eqn (12):

$$
T C=\sum_{i=1}^{m} \sum_{j=1, j \neq i}^{m} T R C_{i j}+\sum_{i=1}^{m} H C_{i}+\sum_{i=1}^{m} S C_{i},
$$

where $i$ and $j$ are different fabricators in the supply chain system. Note that the present work considers external supply (from the original suppliers) besides the transshipments to cover fabricators demand. The proposed supply chain framework can also be applied to different precast fabrication materials (such as rebar, cement, gravel, sand, pre-stressing cables, and tendons, etc.) simultaneously. Costs for different materials can be represented using individual cost equation shown in Eqn (12).

\section{Experiments}

\subsection{Design of experiments}

To verify feasibility of the developed transshipment policy analysis model, this research used precast rebar cases to test the model. The specifications for rebar material used in precast fabrication are dissimilar to those cast on sites. As a result, reordering lead time is longer than that for the general rebar used at construction sites. The input data were generated from a hypothetical scenario to create a comprehensive data set. Therefore, the developed transshipment model can be thoroughly tested.

This experiment considered four factors, that is demand variability, multi-manufacturer systems, order lead time, and costs to approximate real situations. Uniform is one of the most frequently used distributions to represent the variability (Banerjee et al. 2003; Hines et al. 2003). Normal distributions were thus used to model the demand variability. Two kinds of uniform distributions were used in this experiment. The first was high demand variability $\left(D_{i} \pm 0.667 D_{i}\right)$ and the second was low demand variability $\left(D_{i} \pm\right.$ $\left.0.333 D_{i}\right)$. Experiments with three, five, and nine manufacturers systems were used to examine the impact of supply chain system size. Three combinational order lead times corresponding to manufacturer systems were simulated. For the three manufacturers' supply chain system, the order lead times were $L_{1}=3$ and $L_{2}=L_{3}=1$. For five manufacturers' system, $L_{1}=L_{2}=3$ and $L_{3}=L_{4}=L_{5}=1$. For the nine manufacturers system, $L_{1}=L_{2}=L_{3}=L_{4}=L_{5}=3$ and $L_{6}=$ $L_{7}=L_{8}=L_{9}=1$. Total cost in this study included holding, transportation, and SCs. In practice, $\mathrm{HC}$ is relatively less than shortage and TCs. As a result, HC was fixed as one per unit in this study. Five combinations of the shortage and TCs were used to experiment with the impacts of shortage and transportation costs together with the $\mathrm{HC}(S C, T R C)$, that is $(4,1),(9,1)$, 
Table 5. Inventory level for the three retailers system

\begin{tabular}{|c|c|c|c|c|c|c|}
\hline \multirow[b]{2}{*}{ Number } & \multirow[b]{2}{*}{ NLS } & \multicolumn{4}{|c|}{ Transshipment strategy } & \multirow[b]{2}{*}{ MA } \\
\hline & & RA & TBAPR I & TIE & TBAPR II & \\
\hline $1-1$ & 316.02 & 315.92 & 315.90 & 315.63 & 315.89 & 315.93 \\
\hline $1-2$ & 316.69 & 316.58 & 316.65 & 316.40 & 316.64 & 316.63 \\
\hline $1-3$ & 316.14 & 316.06 & 316.06 & 315.82 & 316.06 & 316.06 \\
\hline $1-4$ & 316.67 & 316.57 & 316.60 & 316.37 & 316.60 & 316.59 \\
\hline $1-5$ & 316.01 & 315.87 & 315.94 & 315.63 & 315.90 & 315.85 \\
\hline $2-1$ & 330.28 & 330.23 & 330.23 & 330.09 & 330.23 & 330.21 \\
\hline $2-2$ & 331.26 & 331.21 & 331.21 & 331.04 & 331.21 & 331.20 \\
\hline $2-3$ & 331.38 & 331.32 & 331.35 & 331.19 & 331.34 & 331.34 \\
\hline $2-4$ & 330.85 & 330.82 & 330.81 & 330.69 & 330.81 & 330.80 \\
\hline $2-5$ & 330.95 & 330.90 & 330.88 & 330.72 & 330.90 & 330.89 \\
\hline $3-1$ & 319.78 & 319.70 & 319.74 & 319.58 & 319.72 & 319.73 \\
\hline $3-2$ & 318.80 & 318.74 & 318.75 & 318.61 & 318.75 & 318.74 \\
\hline $3-3$ & 319.61 & 319.53 & 319.55 & 319.41 & 319.57 & 319.54 \\
\hline $3-4$ & 319.71 & 319.67 & 319.66 & 319.51 & 319.65 & 319.64 \\
\hline $3-5$ & 319.80 & 319.75 & 319.73 & 319.59 & 319.74 & 319.72 \\
\hline $4-1$ & 316.89 & 316.59 & 316.74 & 315.73 & 316.67 & 316.48 \\
\hline $4-2$ & 315.71 & 315.37 & 315.51 & 314.49 & 315.46 & 315.29 \\
\hline $4-3$ & 316.82 & 316.49 & 316.66 & 315.64 & 316.56 & 316.47 \\
\hline $4-4$ & 316.82 & 316.43 & 316.66 & 315.67 & 316.61 & 316.50 \\
\hline $4-5$ & 316.32 & 315.92 & 316.14 & 315.16 & 316.07 & 316.04 \\
\hline $5-1$ & 331.32 & 331.11 & 331.19 & 330.40 & 331.16 & 331.11 \\
\hline $5-2$ & 330.26 & 329.97 & 330.15 & 329.36 & 330.03 & 329.99 \\
\hline $5-3$ & 329.76 & 329.57 & 329.60 & 328.91 & 329.63 & 329.50 \\
\hline $5-4$ & 331.26 & 331.03 & 331.15 & 330.43 & 331.05 & 331.06 \\
\hline $5-5$ & 331.27 & 331.10 & 331.15 & 331.42 & 331.05 & 331.04 \\
\hline $6-1$ & 318.34 & 317.92 & 318.11 & 317.25 & 318.01 & 317.93 \\
\hline $6-2$ & 318.65 & 318.33 & 318.50 & 317.70 & 318.41 & 318.36 \\
\hline $6-3$ & 322.06 & 321.74 & 321.93 & 321.10 & 321.79 & 321.78 \\
\hline $6-4$ & 320.80 & 320.52 & 320.68 & 319.98 & 320.64 & 320.58 \\
\hline $6-5$ & 320.65 & 320.26 & 320.45 & 319.60 & 320.43 & 320.33 \\
\hline
\end{tabular}

Note: Unit in this table is one per unit holding cost.

$(9,3),(90,10)$, and $(20,100)$. These combinations provide opportunities with relatively small and relatively large shortage and/or transportation costs. The simulation experimented with 90 combinations $(2 \times 3 \times 5 \times 3)$ of situations. Table 1 illustrates the parameters used for the three manufacturers.

\subsection{Simulation results}

The simulation implemented each multiple manufacturer system 300 times in 20-day periodic reviews. The simulation result trends for five and nine manufacturers were similar to that for the three retailers. This study therefore only demonstrated full results for the three manufacturer system. Table 2 shows the total costs average for the three manufacturers. Tables 3-5 display the shortage amount, transshipment frequency, and inventory level, respectively.

\subsection{Discussion}

This research evaluated the most advantageous strategy using the total cost shown in Eqn (12), comprised of transportation, holding, and SCs. Simulation results in Table 2 show that TBAPR I outperforms the other strategies whether demand variability is high (see numbers 4-1 4-4, 5-1 5-4, 6-1 6-4) or low (see numbers 1-1 1-4, 2-1 2-4, 3-1 3-4). In the same table, the strategy also outshines the others in different order lead times (see numbers 3-1 3-4, 6$1 \sim 6-4)$. The transshipment total cost priority rank is TBAPR I, MA, TBAPR II, TIE, RA, and NLS. From Table 2, the total cost increases with the order lead time because the order lead time increases the inventory level and thus raises the $\mathrm{HC}$ (see numbers $2-1 \sim 2-5,5-1 \sim 5-5$ ). But the NLS strategy surpasses TBAPR I when the transportation cost is more expensive than the shortage cost (see numbers 1-5, $2-5,3-5,4-5,5-5,6-5)$. In this situation, waiting for the next refill is more beneficial for retailers implementing lateral transshipment. The TBAPR I strategy induces minimum cost, which can also be observed from the material shortage amount (see Table 3) and inventory level (see Table 5). In Table 4, this strategy has the most frequent transshipment, providing manufacturers with opportunities to balance the supply 
chain system. The simulation results for three, five, and nine multi-retailer systems obey the same trends. The strategy priority for different multiple retailer systems is also the same, showing that the size of the supply chain system has less influence on transshipment strategy selection. However, the shortage amount for the three manufacturer systems is higher than that for the five manufacturer systems, higher than that for nine. A reasonable explanation is that supply chain size influences the shortage amount, enhancing transshipment agility by a greater number of manufacturers. Four operational rules are developed based on the above simulation results. These rules may provide an easy-to-use procedure for precast fabricators to make transshipment decision when lack materials:

Rule 1: If transshipment lead time is longer than reorder lead time, lateral transshipment is not required;

Rule 2: Providers should consider future demand and only transship extra materials;

Rule 3: Providers with the most sufficient ship materials to those with the most shortage to immediately replenish reserves;

Rule 4: Transportation, holding, and SCs have a crucial impact on transshipment decision.

\section{Conclusions}

This study developed a framework for applying lateral transshipment to precast construction. A central warehouse with multiple precast fabricators was simulated in this study. To eliminate imminent shortage, the developed framework transships materials from fabricators with sufficient supplies to others starved for materials. This research analyzed six strategies considering uncertain demand, diverse order lead time, and the scale of supply chain systems. Simulation results show that the TBAPR I strategy induces minimum inventory and material SCs when implementing lateral transshipment. Previous studies in multi-echelon supply chains have highlighted that lateral transshipment reduces both inventory and SCs. However, this study found that lateral transshipment is not always beneficial in the construction industry where it is more appropriate for fabricators located in nearby areas. The simulation results also showed that longer order lead time increases total cost. For a larger multiple manufacture supply chain system, a greater number of fabricators participating in the corporate system enhances the amount of material shortages that can be reduced. Four operational rules developed based on these simulation results may provide precast fabricators with a quick procedure to make transshipment decisions without complex computer simulations.

This research suggested that precast fabricators mitigate the material shortage risk and decrease inventory cost based on a supply chain framework. However, successful application cannot be achieved without benefit sharing and managerial operations, which can be studied in the future. Moreover, in addition to the transshipment strategies analyzed in this paper, more rules can be developed specifically for the needs of fabricators. A web-based inventory management system can also be developed for allied precast fabricators to understand the real-time inventory status in the network.

\section{Acknowledgements}

This research was funded by grants NSC 94-2218-E-212011, NSC 95-2221-E-212-051, NSC 96-2221-E-020-030, and NSC 97-2221-E-020-036- MY2 from the National Science Council (Taiwan), whose support is gratefully acknowledged. Any opinions, findings, conclusions, or recommendations expressed in this paper are those of the author and do not reflect the views of the National Science Council. The writer would also like to thank the investigated precast fabricator for supporting this study. Special thanks are due to student Yu-Dian Li for data analysis, equations formulation, and simulation programming.

\section{References}

Ameli, M. S. J.; Azad, N.; Rastpour, A. 2009. Designing a supply chain network model with uncertain demands and lead times, Journal of Uncertain Systems 3(2): 123-130.

Axsäter, S. 1990a. Modeling emergency lateral transshipments in inventory systems, Management Science 36(11): 1329-1338. http://dx.doi.org/10.1287/mnsc.36.11.1329

Axsäter, S. 1990b. Simple solution procedures for a class of two-echelon inventory problems, Operations Research 38(1): 64-69. http://dx.doi.org/10.1287/opre.38.1.64

Axsäter, S. 2006. A simple procedure for determining order quantities under a fill rate constraint and normally distributed lead-time demand, European Journal of Operational Research 174(1): 480-491.

http://dx.doi.org/10.1016/j.ejor.2005.01.037

Banerjee, A.; Burton, J.; Banerjee, S. 2003. A simulation study of lateral shipments in single supplier, multiple buyers supply chain networks, International Journal of Production Economics 81-82: 103-114. http://dx.doi.org/10.1016/S0925-5273(02)00366-3

Blakemore, F. P.; Konda, T. F. 2010. Design-build replacement of US-90 bridge over Bay St. Louis, Mississippi, Transportation Research Record: Journal of the Transportation Research Board 2201: 106-112. http://dx.doi.org/10.3141/2201-12

Bloomberg, D. J.; Murray, A.; Hanna, J. B. 1998. The management of integrated logistics: a Pacific Rim perspective. 2nd ed. Sydney: Prentice Hall-Sprint Print. $311 \mathrm{p}$.

Burton, J.; Banerjee, A. 2005. Cost-parametric analysis of lateral transshipment policies in two-echelon supply chains, International Journal of Production Economics 93-94: 169-178. http://dx.doi.org/10.1016/j.ijpe.2004.06.015 
Cooper, R. G. 1994. Perspective third - generation new product processes, Journal of Product Innovation Management 11(1): 3-14. http://dx.doi.org/10.1016/0737-6782(94)90115-5

Fredendall, L. D. 2001. Basics of supply chain management. Boca Raton, Florida: St. Lucie Press/APICS series on resource management, $250 \mathrm{p}$.

Hanlon, J.; Fernandez, P.; Dolan, C. W. 2009. Precast concrete building system components for the Westin resort hotel, part 2: Design and construction, $P C I$ Journal 54(3): 143-152.

Herer, Y. T.; Tzur, M. 2001. The dynamic transshipment problem, Naval Research Logistics 48(5): 386-408. http://dx.doi.org/10.1002/nav.1025

Herer, Y. T.; Tzur, M. 2003. Optimal and heuristic algorithms for the multi-location dynamic transshipment problem with fixed transshipment costs, IIE Transactions 35(5): 419-432. http://dx.doi.org/10.1080/07408170304389

Hines, W. W.; Montgomery, D. C.; Goldsman, D. M.; Borror, C. M. 2003. Probability and statistics in engineering. 4th ed. New York: Wiley, 672 p.

Hopp, W. J.; Spearman, M. L. 2000. Factory physics: foundations of manufacturing management. 2nd ed. Chicago: McGraw Hill, 600 p.

Im, K. S.; Han, S. H.; Koo, B.; Jung, D. Y. 2009. Formulation of a pull production system for optimal inventory control of temporary rebar assembly plants, Canadian Journal of Civil Engineering 36(9): 1444-1458.

http://dx.doi.org/10.1139/L09-072

Ko, C.-H. 2006. Buffer evaluation for demand variability using fuzzy logic, in Proc. of the 14th Annual Conference of the International Group for Lean Construction, Santiago, Chile, 255-264.

Ko, C.-H. 2010. An integrated framework for reducing precast fabrication inventory, Journal of Civil Engineering and Management 16(3): 418-427. http://dx.doi.org/10.3846/jcem.2010.48

Ko, C.-H. 2011. Production control in precast fabrication: considering demand variability in production schedules, Canadian Journal of Civil Engineering 38(2): 191-199. http://dx.doi.org/10.1139/L10-123

Ko, C. H.; Ballard, G. 2004. Demand variability and fabrication lead time: descriptive research, phase I. Berkeley, CA: University of California at Berkeley, $114 \mathrm{p}$.

Ko, C.-H.; Wang, S.-F. 2011. Precast production scheduling using multi-objective genetic algorithms, Expert Systems with Applications 38(7): 8293-8302. http://dx.doi.org/10.1016/j.eswa.2011.01.013

Lee, Y. H.; Jung, J. W.; Jeon, Y. S. 2007. An effective lateral transshipment policy to improve service level in the supply chain, International Journal of Production Economics 106(1): 115-126. http://dx.doi.org/10.1016/j.ijpe.2006.05.007

Li, Y. D. 2005. Strategy analysis of lateral transshipment for material risk pooling. MS Thesis. Da-Yeh University, Taiwan (in Chinese).
Manzini, R.; Gamberi, M.; Gebennini, E.; Regattieri, A. 2008. An integrated approach to the design and management of a supply chain system, The International Journal of Advanced Manufacturing Technology 37(5-6): 625-640.

http://dx.doi.org/10.1007/s00170-007-0997-9

Oyetunji, A. A.; Anderson, S. D. 2006. Relative effectiveness of project delivery and contract strategies, Journal of Construction Engineering and Management ASCE 132(1): 3-13.

http://dx.doi.org/10.1061/(ASCE)0733-9364(2006)132: 1(3)

Ross, D. F. 1998. Competing through supply chain management. Springer, $365 \mathrm{p}$.

Sambasivan, M.; Soon, Y. W. 2007. Causes and effects of delays in Malaysian construction industry, International Journal of Project Management 25(5): 517526.

http://dx.doi.org/10.1016/j.ijproman.2006.11.007

Shu, H. S. 2001. Applying supply chain management theories in construction material planning: a case study of precast steel material. MS Thesis. National Taiwan University, Department of Civil Engineering (in Chinese).

Silver, E. A.; Pyke, D. F.; Peterson, R. 1998. Inventory management and production planning and scheduling. 3rd ed. New York: Wiley Press, 784 p.

Tagaras, G. 1999. Pooling in multi-location periodic inventory distribution systems, Omega 27(1): 39-59. http://dx.doi.org/10.1016/S0305-0483(98)00030-9

Tah, J. H. M.; Carr, V. 2001. Towards a framework for project risk knowledge management in the construction supply chain, Advances in Engineering Software 32(10-11): 835-846. http://dx.doi.org/10.1016/S0965-9978(01)00035-7

Toktaş-Palut, P.; Ülengin, F. 2011. Coordination in a twostage capacitated supply chain with multiple suppliers, European Journal of Operational Research 212(1): 4353. http://dx.doi.org/10.1016/j.ejor.2011.01.018

Ula, T. A.; Smadi, A. A. 2003. Identification of periodic moving-average models, Communications in StatisticsTheory and Methods 32(12): 2465-2475. http://dx.doi.org/10.1081/STA-120025388

Verma, A.; Agarwal, V. K. 2005. Bulk materials handling for port applications-a review, Bulk Solids Handling 25(1): 34-37.

Vollmann, T. E.; Berry, W. L.; Whybark, D. C.; Jacobs, F. R. 2004. Manufacturing planning and control systems for supply chain management. 5th ed. New York: McGrawHill, 598 p.

Yeo, K. T.; Ning, J. H. 2002. Integrating supply chain and critical chain concepts in engineer-procure-construct (EPC) projects, International Journal of Project Management 20(4): 253-262. http://dx.doi.org/10.1016/S0263-7863(01)00021-7

Zhang, X. Y. 1992. Development and application of purchasel sale/inventory systems. MS thesis. National Chung Hsing University, Department of Business Administration, Taichung, Taiwan (in Chinese). 
Chien-Ho KO. Associate Professor in the Department of Civil Engineering at National Pingtung University of Science and Technology, Taiwan. He received a BS in Construction Engineering from National Taiwan Institute of Technology in 1997, and an MS and PhD from National Taiwan University of Science and Technology in 1999 and 2002, respectively. Dr Ko was a Postdoctoral Research Fellow at the University of California at Berkeley from 2004 to 2005, sponsored by the Ministry of Education, Taiwan. He is a registered Professional Engineer of fire protection and a member of Taipei Association of Fire Protection Engineer. Dr Ko is a co-founder and research director at Lean Construction Institute-Taiwan, and co-founder and executive director at Lean Construction Institute-Asia. He is serving as Editorial Board Member for more than seven international journals. Dr Ko is also serving as Editor-inChief of the Journal of Engineering, Project, and Production Management (EPPM-Journal). His research has centered around four areas: (1) lean construction; (2) computational algorithms; (3) robotics; and (4) engineering education. 